\title{
Carbon/ $\mathrm{Cr}_{2} \mathrm{O}_{3}$ nanocrystal Composites as an Anode with Improved Lithium Storage Performance
}

\author{
Yongtao Li $i^{1,2,3}$, Yuzhou Liu ${ }^{1}$, Chenyong Shi ${ }^{2}$, Xiuqian Liang ${ }^{2}$, Liqing Liu ${ }^{1,3, *}$, Hongguang Zhang ${ }^{1,3}$, \\ Xuemin $\mathrm{He}^{1,3}$ and Yanwen $\mathrm{Ma}^{4}$ \\ ${ }^{1}$ College of Science, Nanjing University of Posts and Telecommunications, Nanjing 210023, P. R. \\ China. \\ ${ }^{2}$ College of Electronic Science and Engineering, Nanjing University of Posts and \\ Telecommunications, Nanjing 210023 P. R. China. \\ ${ }^{3}$ New Energy Technology Engineering Laboratory of Jiangsu Province, Nanjing University of Posts \\ and Telecommunications, Nanjing 210023, P. R. China. \\ ${ }^{4}$ College of material science and Engineering, Nanjing University of Posts and Telecommunications, \\ Nanjing 210023 P. R. China. \\ *E-mail: liulq@njupt.edu.cn
}

Received: 5 November 2021 / Accepted: 22 December 2021 / Published: 2 February 2022

Carbon-coated $\mathrm{Cr}_{2} \mathrm{O}_{3}$ composites were prepared by the hydrothermal reaction of ammonium chromate $\left(\left(\mathrm{NH}_{4}\right)_{2} \mathrm{CrO}_{4}\right)$ and sucrose to form a polymer that was then annealed and carbonized at $600^{\circ} \mathrm{C}$ under an argon atmosphere to generate nanoparticles of the anodic nanocomposites. The results of electrochemical test showed that the nanocomposite with $49.0 \mathrm{wt} \%$ carbon content has more stable and excellent electrochemical performance as the anode material for lithium-ion batteries..The diameters of the $\mathrm{Cr}_{2} \mathrm{O}_{3}$ crystals in the nanocomposites were $20-50 \mathrm{~nm}$, which helped to modulate the volume expansion of $\mathrm{Cr}_{2} \mathrm{O}_{3}$ crystals beneath the external carbon shell and ultimately greatly improved the lithium storage performance and discharge/charge (i.e. lithiation/delithiation) cycling stability of the nanocomposites. The specific capacity of the nanocomposite with carbon content of $49.0 \mathrm{wt} \%$ was 542 $\mathrm{mAh} \cdot \mathrm{g}^{-1}$ after 300 cycles, which was significantly higher than the capacity of the bare $\mathrm{Cr}_{2} \mathrm{O}_{3}$ crystals. In addition, as the cycle number increased, the specific capacity of the battery also steadily increased. These results indicated that the composite material is a promising candidate as an anode material for lithiumion batteries.

Keywords: Carbon-coated; Lithium storage performance; Lithium-ion batteries;

\section{$\underline{\text { FULL TEXT }}$}

(C) 2022 The Authors. Published by ESG (www.electrochemsci.org). This article is an open access article distributed under the terms and conditions of the Creative Commons Attribution license (http://creativecommons.org/licenses/by/4.0/). 